\title{
Rotational Soft-Tissue Balance Is Highly Correlated with Rotational Kinematics in Total Knee Arthroplasty
}

\author{
Tomofumi Kinoshita, MD ${ }^{1}$ Kazunori Hino, PhD, MD ${ }^{1}$ Tatsuhiko Kutsuna, PhD, MD ${ }^{1}$ \\ Kunihiko Watamori, $\mathrm{MD}^{1}$ Hiromasa Miura, PhD, MD ${ }^{1}$ \\ ${ }^{1}$ Department of Orthopedic Surgery, Ehime University Graduate \\ School of Medicine, Ehime, Japan \\ Address for correspondence Kazunori Hino, PhD, MD, Department of \\ Orthopedic Surgery, Ehime University Graduate School of Medicine, \\ J Knee Surg 2023;36:47-53. \\ Shitsukawa, Toon, Ehime 791-0295, Japan \\ (e-mail: taimisaki@gmail.com).
}

\begin{abstract}
Keywords

- total knee arthroplasty

- soft tissue balance

- rotational kinematics

- cruciate retaining

- posterior stabilized

Recovery of normal knee kinematics is critical for improving functional outcomes and patient satisfaction after total knee arthroplasty (TKA). The kinematics pattern after TKA varies from case to case, and it remains unclear how to reproduce normal knee kinematics. The present study aimed to evaluate rotational knee kinematics and softtissue balance using a navigation system and to assess the influence of intraoperative soft-tissue balance on the rotational knee kinematics. We evaluated 81 osteoarthritic knees treated with TKA using a posterior stabilized (50 knees) or cruciate retaining (31 knees) prosthesis. Rotational kinematics were assessed at 0, 30, 45, 60, and 90 degrees flexion angles by using a computer-assisted navigation system. Correlation between femorotibial rotational position and measured soft tissue balance was assessed by using Spearman's rank correlation coefficient. Rotational soft-tissue balance (the median angle of rotational stress) was significantly correlated with rotational kinematics (rotational axis of the femur relative to the tibia throughout the range of motion) at all measured angles after TKA. The correlation coefficients between the median angle of rotational stress and rotational kinematics were $0.97,0.80,0.74,0.71$, and 0.70 at 0 , $30,45,60$, and 90 degrees of flexion, respectively ( $p$-values $<0.0001$ in all measured angles). The correlation coefficient increased as the knee approached full extension. Our findings suggest that soft-tissue balance is a key factor for rotational kinematics, following both cruciate-retaining and posterior-stabilized TKA.
\end{abstract}

Total knee arthroplasty (TKA) is one of the most effective treatments for severe osteoarthritis, helping to relieve pain, modify lower limb length, and ensure functional recovery of arthritic knees. ${ }^{1}$ Despite the development of modern TKA techniques, 15 to $30 \%$ of patients are unsatisfied with their surgical outcomes. ${ }^{2}$ Various preoperative, intraoperative, and postoperative factors are associated with patient satisfaction and functional outcomes following TKA. ${ }^{3}$ Some researchers have highlighted the effects of restoring normal knee kinematics after TKA, which plays a significant role in prosthesis durability and patient satisfaction. ${ }^{4-7}$

received

August 7, 2020

accepted after revision

March 12, 2021

article published online

May 15, 2021
Recent advancements in motion analysis technology have enabled more accurate evaluation of knee kinematics. Several studies have employed three-dimensional (3D) methods to investigate knee kinematics, including 3D bone models, radiographic image sequences, and image-matching techniques..$^{8-10}$ Advancements in these measurement have enabled us to understand aspects of normal knee kinematics such as screw-home movement and medial pivot motion in detail. However, previous studies have reported the disappearance of screw-home movement following TKA when compared with normal knee kinematics, as well as changes in varus-valgus

(c) 2021. Thieme. All rights reserved. Thieme Medical Publishers, Inc., 333 Seventh Avenue, 18th Floor, New York, NY 10001, USA
DOI https://doi.org/ 10.1055/s-0041-1729619. ISSN 1538-8506. 
knee kinematics. ${ }^{11}$ Other groups have reported changes in rotational knee kinematics after TKA. ${ }^{12}$ Although there are detailed methods for assessing knee kinematics, the factors leading to the restoration of normal kinematics following TKA remain unclear.

To restore the normal knee kinematics and improve patient satisfaction, new designs and concepts of implants have been developed and their influence on postoperative kinematics have been verified. ${ }^{13-15}$ Nonetheless, few studies have investigated the most appropriate surgical technique or optimal soft-tissue balance for reproducing ideal kinematics. Ewing et $\mathrm{al}^{16}$ highlighted the importance of soft-tissue balance for guiding postoperative knee motion using computer simulations. With respect to the soft-tissue balance in normal knees, Wada et $\mathrm{al}^{17}$ reported that intermediate points of knee laxity under varus-valgus stress and rotational stress were close to the kinematics of a knee joint in normal cadaveric knees. However, to our knowledge, little study has been done to actually assess the effect of rotational soft-tissue balance to postoperative knee kinematics in TKA. Recent studies utilizing navigation systems, computational models, and anatomical methods have improved our understanding of rotational profiles and other kinematic characteristics during TKA. ${ }^{18-20}$ To ensure restoration of normal knee kinematics, it is necessary to analyze and control the intraoperative factors that influence postoperative kinematics.

The present study aimed to evaluate rotational kinematics (rotational axis of the femur relative to the tibia throughout the range of motion) and rotational soft tissue-balance (the median of the maximum internal and external rotation angles of the femur under passive maximum rotational stress) using a navigation system in TKA. Further, we assessed the relationship between rotational kinematics and rotational soft-tissue balance in TKA. We hypothesized that rotational soft-tissue balance would have a significant influence on rotational knee kinematics after TKA.

\section{Materials and Methods}

We analyzed 93 knees in 86 Japanese patients with osteoarthritis who underwent either cruciate-retaining (CR) or posterior-stabilized (PS) TKA (Persona PS, LPS-flex: Zimmer, Warsaw, IN and Persona CR, CR-flex: Zimmer). All procedures were performed by using a medial parapatellar approach and measured resection techniques with a navigation system (Precision Knee Navigation Software version 4.0, Stryker, Kalamazoo, MI). All patients had been diagnosed with medial knee osteoarthritis. To minimize the influence of clinical variables, patients with extension ( $>20$ degrees) restriction $(n=8)$ and valgus deformities $(n=4)$ were excluded. The patient population comprised 60 women and 21 men with a mean age of $74.1 \pm 7.9$ years (range: $45-85$ years). The study population was normally distributed. The average preoperative hip-knee-ankle angle (HKA) was $11.2 \pm 5.7$ degrees in varus knees. The patient characteristics of the included patients are presented in -Table $\mathbf{1}$.

In accordance with procedures outlined in a previous study, ${ }^{21}$ an air tourniquet was inflated to $250 \mathrm{~mm} \mathrm{Hg}$ with
Table 1 Patient characteristics

\begin{tabular}{|l|l|l|l|}
\hline & $\begin{array}{l}\text { CR-TKA } \\
\text { Mean } \pm \text { SD } \\
\text { (range) }\end{array}$ & $\begin{array}{l}\text { PS-TKA } \\
\text { Mean } \pm \text { SD } \\
\text { (range) }\end{array}$ & p-Value \\
\hline Age (years) & $74.1 \pm 7.9$ & $76.0 \pm 7.2$ & \\
\hline$n$ & 31 & 50 & \\
\hline Female/male & $29 / 2$ & $30 / 20$ & $0.01^{\mathrm{a}}$ \\
\hline $\begin{array}{l}\text { Preoperative } \\
\text { HKA angle } \\
\text { (degrees) }\end{array}$ & $\begin{array}{l}9.5 \pm 5.8 \\
(1-27)\end{array}$ & $\begin{array}{l}12.3 \pm 5.4 \\
(3-23)\end{array}$ & \\
\hline $\begin{array}{l}\text { Postoperative } \\
\text { HKA angle } \\
\text { (degrees) }\end{array}$ & $\begin{array}{l}0.2 \pm 1.9 \\
(-3 \text { to } 4)\end{array}$ & $\begin{array}{l}0.7 \pm 2.2 \\
(-4 \text { to } 5)\end{array}$ & 0.21 \\
\hline $\begin{array}{l}\text { Preoperative } \\
\text { Maximum } \\
\text { extension } \\
\text { (degrees) }\end{array}$ & $\begin{array}{l}4.0 \pm 5.5 \\
(0-20)\end{array}$ & $\begin{array}{l}10.2 \pm 6.7 \\
(0-25)\end{array}$ & $<0.0001^{\mathrm{b}}$ \\
\hline $\begin{array}{l}\text { Postoperative } \\
\text { Maximum } \\
\text { extension } \\
\text { (degrees) }\end{array}$ & $\begin{array}{l}0.6 \pm 2.5 \\
(0-10)\end{array}$ & $\begin{array}{l}2.9 \pm 4.8 \\
(0-25)\end{array}$ & $0.002^{\mathrm{b}}$ \\
\hline $\begin{array}{l}\text { Preoperative } \\
\text { Maximum } \\
\text { flexion } \\
\text { (degrees) }\end{array}$ & $\begin{array}{l}134.5 \pm 7.2 \\
(120-145)\end{array}$ & $\begin{array}{l}115.7 \pm 14.4 \\
(80-145)\end{array}$ & $<0.0001^{\mathrm{b}}$ \\
\hline $\begin{array}{l}\text { Postoperative } \\
\text { Maximum } \\
\text { flexion } \\
\text { (degrees) }\end{array}$ & $\begin{array}{l}130.6 \pm 11.0 \\
(100-145)\end{array}$ & $\begin{array}{l}124.5 \pm 13.1 \\
(95-145)\end{array}$ & $0.04^{\mathrm{a}}$ \\
\hline $\begin{array}{l}\text { Tibial slope } \\
\text { after TKA }\end{array}$ & $\begin{array}{l}5.8 \pm 2.1 \\
(4-9)\end{array}$ & $\begin{array}{l}3.8 \pm 1.9 \\
(1-6)\end{array}$ & $0.004^{\mathrm{b}}$ \\
\hline
\end{tabular}

Abbreviations: CR TKA, cruciate-retaining total knee arthroplasty; HKA angle, hip-knee-ankle angle; PS TKA, posterior-stabilized total knee arthroplasty; SD, standard deviation; tibial slope after TKA, postoperative tibial slope after TKA.

Wilcoxon signed-rank test:

${ }^{\mathrm{a}} \mathrm{p}<0.05$.

${ }^{\mathrm{b}} \mathrm{p}<0.01$.

patients under general anesthesia, and specific anatomical reference points were located by anchoring infrared signal transducers into the femur and tibia with pins. A straight skin incision was made to expose the subcutaneous tissue. Registration was performed with osteophytes and soft tissues, and the anterior cruciate ligament was preserved. The anteroposterior and rotational axes of the femur and tibia were identified with respect to femoral and tibial anatomical landmarks. The femoral rotational axis was defined by referring to the average rotation axis of the axis perpendicular to the Whiteside line and the transepicondylar axis. The tibial rotational axis was set parallel to the line connecting one-third of the tibial tubercle to the center of the cut surface. After registration, the joint capsule was temporarily closed by using four suture strands. Mild passive knee flexion was manually applied without angular acceleration while moving the leg from full extension to deep flexion. The rotational axis of the femur relative to the tibia at $0,30,45,60$, and 90 degrees of flexion, and maximum flexion was automatically measured by 
the navigation system, allowing us to evaluate rotational kinematics throughout the range of motion. Positive values indicate external rotation of the femur relative to the tibia, whereas negative values indicate internal rotation of the femur relative to the tibia.

Following this, the distal femur was then cut by using a measured resection technique. For determining the rotational angle of the femoral component, we utilized the surgical transepicondylar axis as the index of femoral rotation. Before surgery, we calculated the gap of angle between the surgical transepicondylar axis and the posterior condylar axis on axial view of computed tomography to determine the rotational angle. With respect to bone resections, the distal femoral cut was made perpendicular to the mechanical axis of the femur, and the proximal tibial cut was made perpendicular to the mechanical axis of the tibia on the basis of the concept of mechanical alignment. After removing the osteophytes, we placed trial components and a trial insert. We typically began with a $10-\mathrm{mm}$ insert (thinnest insert thickness in this TKA procedure). Then, we evaluated knee stability using a manual varus-valgus test throughout extension to deep flexion in that condition. Finally, we performed the POLO test to confirm the stability in 90 degrees flexion position. ${ }^{22}$ We increased size of an insert in cases showing excessive medial laxity and in cases showing excessive flexion laxity. Conversely, in cases showed flexion contracture or in cases in which soft-tissue balance was inappropriate, posterior knee capsule, the medial collateral ligament, or other tissues were carefully and selectively released to achieve intraoperative full extension and correct soft-tissue balance throughout range of motion. ${ }^{23}$ After trial, the components and inserts of the proper thickness were placed in the appropriate position with cement, and the surgical incision was closed. Subsequently, we assessed rotational kinematics using the same procedures performed prior to TKA. In addition, maximum internal and external stress was applied, and the width of the internal-external rotational stress angle of the femur relative to the tibia was evaluated at $0,30,45,60$, and 90 degrees of flexion and maximum flexion. For analyses at 0 degrees of extension, we assessed cases in which complete extension could be achieved. We calculated the median of the maximum internal and external rotation angles of the femur to obtain an index of rotational soft-tissue balance. The median of the maximum internal and external rotation angle refers to the median value between the angle of maximum internal rotation and the angle of maximum external rotation. All data were collected by a single surgeon. To confirm the accuracy of measurements, we calculated the test-retest reliability of the rotational axis of the femur relative to the tibia. Our calculations indicated that the interclass and intraclass correlation coefficients were sufficiently high, with values $>0.9$ at each measured angle of knee flexion. We also evaluated the test-retest reliability of the internal and external angles, observing sufficiently high interclass and intraclass correlation coefficients of $>0.9$ at each measured angle of knee flexion.

This study was approved by the Institutional Review Board of our university (identification number: 1411020), and written informed consent was obtained from all patients.

\section{Statistical Analysis}

Although an arithmetically sufficient normal distribution was observed, nonparametric tests were used due to the small sample size. Comparisons between the CR and PS groups were performed by using nonparametric Wilcoxon's signed-rank tests. Spearman's rank correlation coefficients $(\rho)$ were used to assess the correlation between the rotational axis of the femur relative to the tibia and the median of the maximum internal and external rotation angles. Analyses were conducted by using JMP version 14.0 (SAS Institute, Tokyo, Japan).

\section{Results}

Preoperative and postoperative rotational kinematics (rotational axis of the femur relative to the tibia throughout the range of motion) are presented in - Fig. 1 A, B, respectively. No significant differences in rotational kinematics were observed between the CR and PS groups before and after surgery. The CR and PS groups showed different rotational movement in 0 to 30 degrees flexion, postoperatively. Before TKA, both groups showed femoral external rotation in 0 to 30 degrees flexion. By contrast, only the $\mathrm{CR}$ group showed femoral internal rotation in 0 to 30 degrees flexion, postoperatively.

-Fig. 1C depicts the postoperative median angle of the maximum internal and external rotation stress angles of the femur relative to the tibia (i.e., rotational soft-tissue balance). There was no statistically significant difference between the CR and PS groups. The graphs of rotational kinematics (-Fig. 1B) and rotational soft-tissue balance (-Fig. 1C) were similar in shape. Throughout the range of motion, the rotational axis of the femur relative to the tibia and the median angle of the maximum internal and external rotation angles of the femur relative to the tibia were almost approximate in value.

Rotational kinematics and rotational soft tissue-balance were highly correlated at all angles measured (-Fig. 2A-E). The correlation coefficients between rotational kinematics and soft tissue-balance of the CR and PS groups are listed in -Table 2. The results represent a higher correlation in the knee extension position $(\rho=0.94-0.97)$, whereas the correlation coefficient was getting decreased with higher degrees of flexion $(\rho=0.68-0.74)$.

\section{Discussion}

In the present study, we focused on the influence of softtissue balance on kinematics in TKA surgery. We defined rotational axis of the femur relative to the tibia throughout the range of motion as an index of rotational kinematics. Similarly, the median angle of the maximum internal and external rotation angles of the femur relative to the tibia was defined as an index of rotational soft-tissue balance. Our analyses revealed a strong correlation between rotational kinematics and rotational soft-tissue balance after TKA. Hence, our results support the hypothesis that soft-tissue balance is critical for rotational kinematics following both $C R$ and PS TKA. 

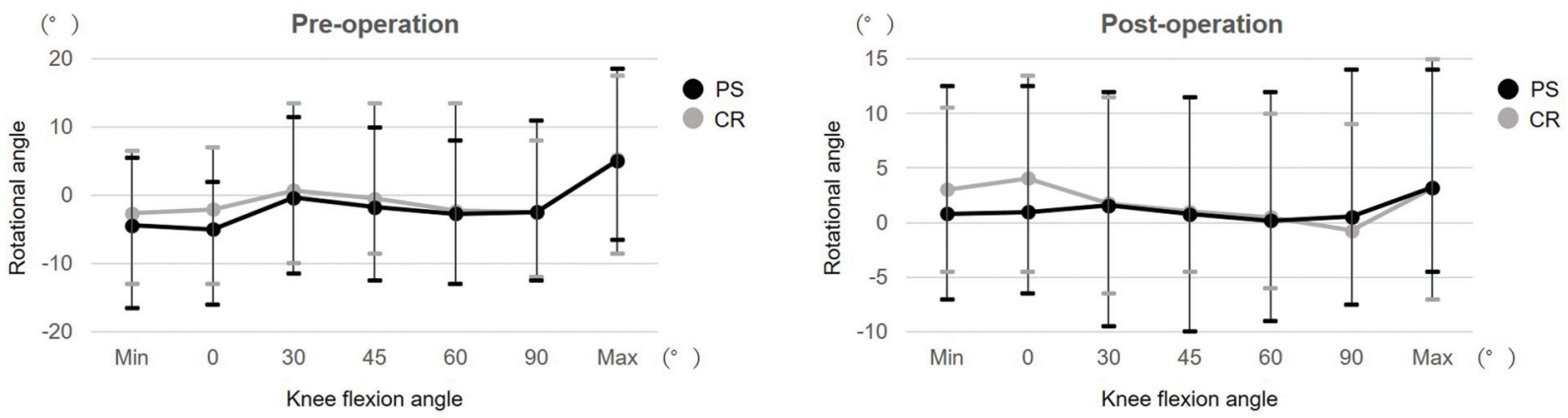

A

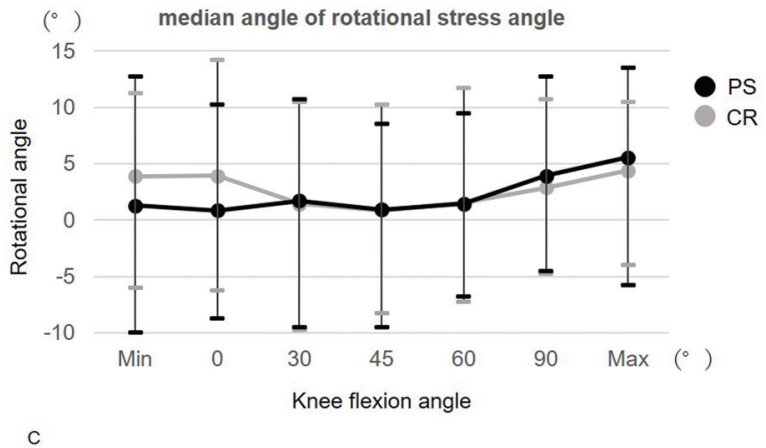

Fig. 1 (A) Preoperative rotational kinematics. (B) Postoperative rotational kinematics. (C) Postoperative median angle of the internal and external rotational stress angle. CR, cruciate-retaining; PS, posterior-stabilized.
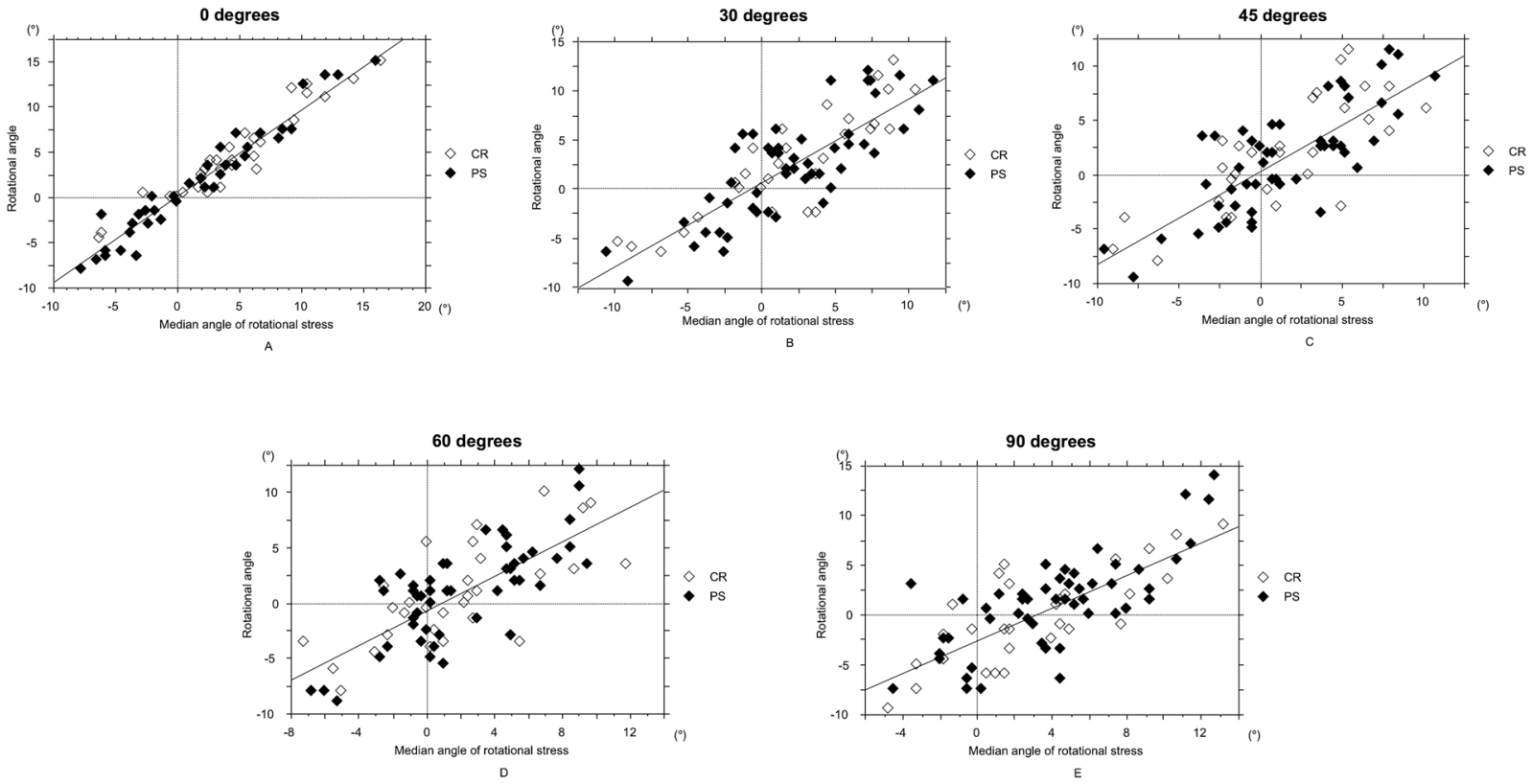

Fig. 2 (A) Scatterplots of the rotational angle and the median angle of rotational stress angle at 0 degrees. (B) Scatterplots of the rotational angle and the median angle of rotational stress angle at 30 degrees. (C) Scatterplots of the rotational angle and the median angle of rotational stress angle at 45 degrees. (D) Scatterplots of the rotational angle and the median angle of rotational stress angle at 60 degrees. (E) Scatterplots of the rotational angle and the median angle of rotational stress angle at 90 degrees.

Various factors influence knee kinematics following surgery, including the shape of the insert, postcam design, and placement of the component. ${ }^{24-28}$ In addition, the implant design exerts a great effect on knee kinematics, and new designs and concepts have been develop to ensure more complete restoration of normal knee kinematics. ${ }^{29}$ However, to our knowledge, no previous studies have identified the most appropriate surgical technique or soft-tissue balance for restoring normal knee kinematics in TKA. The properties of ligaments and soft tissue, along with the force-generating properties of muscle, considerably influence kinematics. However, these factors are known to vary from patient to patient, highlighting the need to 
Table 2 Correlation coefficients between the rotational angle during the rotational kinematics assessment and the median angle of rotational stress at each flexion angle

\begin{tabular}{|l|l|l|l|l|l|l|}
\hline \multirow{2}{*}{ Range of motion (degrees) } & \multicolumn{2}{|l|}{ Total } & \multicolumn{2}{l|}{ CR } & \multicolumn{2}{l|}{ PS } \\
\cline { 2 - 7 } & $\boldsymbol{\rho}$ & $\boldsymbol{p}$-Value & $\boldsymbol{\rho}$ & $\boldsymbol{p}$-Value & $\boldsymbol{\rho}$ & $\boldsymbol{p}$-Value \\
\hline 0 & 0.97 & $<0.0001$ & 0.94 & $<0.0001$ & 0.97 & $<0.0001$ \\
\hline 30 & 0.80 & $<0.0001$ & 0.85 & $<0.0001$ & 0.76 & $<0.0001$ \\
\hline 45 & 0.74 & $<0.0001$ & 0.76 & $<0.0001$ & 0.72 & $<0.0001$ \\
\hline 60 & 0.71 & $<0.0001$ & 0.71 & $<0.0001$ & 0.71 & $<0.0001$ \\
\hline 90 & 0.70 & $<0.0001$ & 0.74 & $<0.0001$ & 0.68 & $<0.0001$ \\
\hline
\end{tabular}

Abbreviations: CR, cruciate-retaining; PS, posterior-stabilized.

tailor surgical procedures to each patient. While the placement and design of the implant, angle of bone cutting, and soft-tissue balance are important, these elements cannot be used in isolation to direct evaluations and predictions of kinematics given their interrelationships. The use of a navigation system to recognize and control multiple intraoperative factors may therefore allow surgeons to reproduce ideal kinematics.

Among these multiple factors, soft-tissue balance should be carefully controlled intraoperatively. Previous studies have highlighted the importance of medial stability for ensuring proper soft-tissue balance during surgery and optimal clinical outcomes. ${ }^{30}$ Although it is well known that medial stability during extension can affect both patient satisfaction and the longevity of TKA, recent studies have suggested that proper rotational soft-tissue balance throughout flexion is also critical. Ishida et $\mathrm{al}^{4}$ proposed that femorotibial rotation at 90 degrees of flexion is associated with the maximum postoperative flexion angle, suggesting that flexibility of rotational soft tissues leads to improvements in maximum flexion angle and clinical results. In addition, Inui et $\mathrm{al}^{31}$ assessed medial pivot motion in their study of guided-motion TKA, demonstrating that a tight flexion gap in TKA prevents femoral external rotation relative to the tibia throughout flexion. Our results are consistent with these findings, in that rotational movement such as medial pivot motion required adequate rotational flexibility and medial rotational stability during flexion. The rotational axis of the femur relative to the tibia during medial pivot motion represents femoral external rotation during flexion. Our results suggest that, to achieve femoral external rotation during flexion, the median of the internal and external rotation stress angle of the femur relative to tibia (rotational soft-tissue balance) should represent external rotation according to knee flexion. Thus, intraoperative management of soft-tissue balance should focus on maintaining medial rotational stability and adequate lateral rotational laxity to induce the ideal femoral external rotation. Unnecessary medial soft-tissue release leads to medial rotational instability, which can in turn lead to paradoxical motion rather than normal knee kinematics. In summary, based on the results of the present study, we may be able to tolerate some lateral rotational laxity and should ensure medial rotational stability throughout range of motion to induce the femoral external rotation during flexion.
For ideal postoperative rotational kinematics, previous reports have already discussed the optimal rotational softtissue balance in TKA. Kamenaga et $\mathrm{al}^{32}$ reported that medial gap at 60, 90 degrees negatively correlated with postoperative internal rotation of tibia in PS TKA, demonstrating the importance of medial stability for inducing femoral external rotation (tibial internal rotation). Matsuzaki et al $^{33}$ studied the relationship between varus ligament balance and tibial internal rotation, and found that lateral laxity led to femoral external rotation in CR TKA. While these reports supported the results of the present study, the surgical theory to intentionally adjust rotational laxity remains unclear. The deep MCL and the popliteus tendon play important roles in rotational stability. ${ }^{34}$ Lutz et $\mathrm{l}^{35}$ reported the stabilizing role of the iliotibial band, its Kaplan fibers, and surrounding capsular ligament complex for tibial internal rotation. According to a previous paper, ${ }^{35}$ selective release and control of soft-tissue balance may restore the optimal femoral external rotation. Nevertheless, it is unknown to what extent the release of these structure can affect rotational stability. Moreover, the results of the present study represent the correlation coefficient decreasing with knee flexion. One reason for this is that it is possible that the stabilizing function of the ligament, which prescribes the rotational stability may have been affected by the amount of bone resection or by changes of alignment after TKA, especially in flexion. The investigation of such uncertainty of the rotational kinematics after TKA might lead to the intraoperative optimal control of rotational kinematics in TKA surgery.

Among the strengths of our study is the use of navigation system, which enabled precise evaluation of the rotational position throughout flexion movements. In addition, by using the same coordinate system pre- and postoperatively, we were able to measure the precise angle of knee flexion throughout the range of motion. Furthermore, the strength of present study is the intraoperative evaluation for patients underwent TKA. Although previous report has proved the relationship between kinematics and knee laxity, ${ }^{16}$ the present study showed the novelty in that we provide sufficient evidence to say that rotational soft-tissue balance significantly correlates with postoperative knee kinematics. Notably, similar results were observed in the CR and PS groups, and rotational soft-tissue balance was observed to exert a critical effect on the rotational knee kinematics in TKA. A knee joint is an exquisite structure 
that represents a complex kinematics, retaining balance of the musculoskeletal system. Dye et $\mathrm{al}^{36}$ proposed the theory of "envelope of function" which showed the range of load that can be applied in a given period without overload. The theory is the concept of homeostasis in human joints. In the present study, we demonstrated that the median of rotational stress angle predicts the rotational kinematics after TKA. This suggests that the median point of rotational laxity may be a comfortable position of the femur relative to the tibia throughout range of motion in TKA. Our result may also derive from the homeostasis of a knee joint. That is to say, the present study found that the homeostasis of a knee joint found in the normal knee ${ }^{16}$ was observed even after TKA.

The present study also had some limitations. First, we assessed rotational kinematics and soft-tissue balance under unloaded conditions, under general anesthesia, and with an air tourniquet. Therefore, we were unable to evaluate the influence of load and muscle strength on kinematics during surgery, and it is unclear whether the conditions we used produced the same knee kinematics as those employed during daily movements. However, Wada et $\mathrm{al}^{37}$ demonstrated that postoperative loadbased kinematics could be predicted based on intraoperative assessments, despite the lack of loading. This report supports the results of our study showing that soft-tissue balance can be a key factor in the restoration of normal knee kinematics. Second, our study only included patients treated for varus-type arthritis, and we did not assess effects on clinical outcomes. Finally, the results were obtained by a single investigator, and the stress force was not standardized. These limitations may restrict the generalizability of the results. Thus, further research is required to determine the optimal soft-tissue balance for restoring normal knee kinematics.

\section{Conclusion}

Our results revealed a strong correlation between rotational soft-tissue balance and rotational kinematics for both CR and PS TKA procedures. These findings indicate that the normal rotational kinematics of the knee can be restored by controlling soft-tissue balance during surgery. Furthermore, we should ensure medial rotational stability throughout the range of motion for inducing ideal rotational movement.

\section{Note}

The procedures in the study were undertaken in accordance with the ethical standards of the Helsinki Declaration and had been approved by the local ethical committee. Informed consent was obtained from all individual participants included in the study.

\section{Funding}

K.H. reports personal fees from null outside the submitted work. H.M. reports personal fees from null outside the submitted work.

\section{Conflict of Interest}

None declared.

\section{References}

1 Insall JN, Binazzi R, Soudry M, Mestriner LA. Total knee arthroplasty. Clin Orthop Relat Res 1985;(192):13-22

2 Bourne RB, Chesworth BM, Davis AM, Mahomed NN, Charron KD. Patient satisfaction after total knee arthroplasty: who is satisfied and who is not? Clin Orthop Relat Res 2010;468(01):57-63

3 Baker PN, van der Meulen JH, Lewsey J, Gregg PJNational Joint Registry for England and Wales Data from the National Joint Registry for England and Wales. The role of pain and function in determining patient satisfaction after total knee replacement. J Bone Joint Surg Br 2007;89(07):893-900

4 Ishida K, Shibanuma N, Matsumoto T, et al. Navigation-based tibial rotation at 90 degrees of flexion is associated with better range of motion in navigated total knee arthroplasty. Knee Surg Sports Traumatol Arthrosc 2016;24(08):2447-2452

5 Nishio Y, Onodera T, Kasahara Y, Takahashi D, Iwasaki N, Majima T. Intraoperative medial pivot affects deep knee flexion angle and patient-reported outcomes after total knee arthroplasty. J Arthroplasty 2014;29(04):702-706

6 Konno T, Onodera T, Nishio Y, Kasahara Y, Iwasaki N, Majima T. Correlation between knee kinematics and patellofemoral contact pressure in total knee arthroplasty. J Arthroplasty 2014;29(12): 2305-2308

7 Meneghini RM, Deckard ER, Ishmael MK, Ziemba-Davis M. A dualpivot pattern simulating native knee kinematics optimizes functional outcomes after total knee arthroplasty. J Arthroplasty 2017;32(10):3009-3015

8 Johal P, Williams A, Wragg P, Hunt D, Gedroyc W. Tibio-femoral movement in the living knee. A study of weight bearing and nonweight bearing knee kinematics using 'interventional' MRI. J Biomech 2005;38(02):269-276

9 Kim HY, Kim KJ, Yang DS, Jeung SW, Choi HG, Choy WS. Screwhome movement of tibiofemoral joint during normal gait: threedimensional analysis. Clin Orthop Surg 2015;7(03):303-309

10 Murakami K, Hamai S, Okazaki K, et al. In vivo kinematics of healthy male knees during squat and golf swing using imagematching techniques. Knee 2016;23(02):221-226

11 Siston RA, Giori NJ, Goodman SB, Delp SL. Intraoperative passive kinematics of osteoarthritic knees before and after total knee arthroplasty. J Orthop Res 2006;24(08):1607-1614

12 Hamada D, Wada K, Takasago T, et al. Native rotational knee kinematics are lost in bicruciate-retaining total knee arthroplasty when the tibial component is replaced. Knee Surg Sports Traumatol Arthrosc 2018;26(11):3249-3256

13 Heyse TJ, Slane J, Peersman G, et al. Kinematics of a bicruciateretaining total knee arthroplasty. Knee Surg Sports Traumatol Arthrosc 2017;25(06):1784-1791

14 Koh YG, Son J, Kwon SK, Kim HJ, Kwon OR, Kang KT. Preservation of kinematics with posterior cruciate-, bicruciate- and patientspecific bicruciate-retaining prostheses in total knee arthroplasty by using computational simulation with normal knee model. Bone Joint Res 2017;6(09):557-565

15 Samy DA, Wolfstadt JI, Vaidee I, Backstein DJ. A retrospective comparison of a medial pivot and posterior-stabilized total knee arthroplasty with respect to patient-reported and radiographic outcomes. J Arthroplasty 2018;33(05):1379-1383

16 Ewing JA, Kaufman MK, Hutter EE, et al. Estimating patientspecific soft-tissue properties in a TKA knee. J Orthop Res 2016;34(03):435-443

17 Wada K, Hamada D, Takasago T, et al. Rotational and varus-valgus laxity affects kinematics of the normal knee: A cadaveric study. J Orthop Surg (Hong Kong) 2019;27(03):2309499019873726

18 Graichen H. Navigation in TKA surgery - evolutionary technique or blind alley? J Orthop 2015;12(01):1-6

19 Hutt JR, LeBlanc MA, Massé V, Lavigne M, Vendittoli PA. Kinematic TKA using navigation: Surgical technique and initial results. Orthop Traumatol Surg Res 2016;102(01):99-104 
20 Hetaimish BM, Khan MM, Simunovic N, Al-Harbi HH, Bhandari M, Zalzal PK. Meta-analysis of navigation vs conventional total knee arthroplasty. J Arthroplasty 2012;27(06):1177-1182

21 Hino K, Kutsuna T, Watamori K, et al. Varus-valgus stability at 90 degrees flexion correlates with the stability at midflexion range more widely than that at 0 degrees extension in posterior-stabilized total knee arthroplasty. Arch Orthop Trauma Surg 2017;137(10):1429-1434

22 Scott RD, Chmell MJ. Balancing the posterior cruciate ligament during cruciate-retaining fixed and mobile-bearing total knee arthroplasty: description of the pull-out lift-off and slide-back tests. J Arthroplasty 2008;23(04):605-608

23 Insall JN, Easley ME. Surgical techniques and instrumentation in total knee arthroplasty. In: Insall JN, Scott WN, eds. Surgery of the Knee. Philadelphia: Churchill Livingstone; 2011:1553-1620

24 Chouteau J, Lerat JL, Testa R, Moyen B, Fessy MH, Banks SA. Mobile-bearing insert translational and rotational kinematics in a PCL-retaining total knee arthroplasty. Orthop Traumatol Surg Res 2009;95(04):254-259

25 Koh YG, Nam JH, Kang KT. Effect of geometric variations on tibiofemoral surface and post-cam design of normal knee kinematics restoration. J Exp Orthop 2018;5(01):53

26 Maderbacher G, Keshmiri A, Springorum HR, Maderbacher H, Grifka J, Baier C. Influence of component rotation in total knee arthroplasty on tibiofemoral kinematics-a cadaveric investigation. J Arthroplasty 2017;32(09):2869-2877

27 Miller MC, Berger RA, Petrella AJ, Karmas A, Rubash HE. Optimizing femoral component rotation in total knee arthroplasty. Clin Orthop Relat Res 2001;(392):38-45

28 Thompson JA, Hast MW, Granger JF, Piazza SJ, Siston RA. Biomechanical effects of total knee arthroplasty component malrotation: a computational simulation. J Orthop Res 2011;29(07): 969-975
29 Digennaro V, Zambianchi F, Marcovigi A, Mugnai R, Fiacchi F, Catani F. Design and kinematics in total knee arthroplasty. Int Orthop 2014;38(02):227-233

30 Tsukiyama H, Kuriyama S, Kobayashi M, et al. Medial rather than lateral knee instability correlates with inferior patient satisfaction and knee function after total knee arthroplasty. Knee 2017; 24(06):1478-1484

31 Inui H, Taketomi S, Yamagami R, Shirakawa N, Kawaguchi K, Tanaka $S$. The relationship between soft-tissue balance and intraoperative kinematics of guided motion total knee arthroplasty. J Knee Surg 2019;32(01):91-96

32 Kamenaga T, Takayama K, Ishida K, et al. Medial knee stability at flexion increases tibial internal rotation and knee flexion angle after posterior-stabilized total knee arthroplasty. Clin Biomech (Bristol, Avon) 2019;68:16-22

33 Matsuzaki T, Matsumoto T, Kubo S, et al. Tibial internal rotation is affected by lateral laxity in cruciate-retaining total knee arthroplasty: an intraoperative kinematic study using a navigation system and offset-type tensor. Knee Surg Sports Traumatol Arthrosc 2014;22(03):615-620

34 Iizawa N, Mori A, Majima T, Kawaji H, Matsui S, Takai S. Influence of the medial knee structures on valgus and rotatory stability in total knee arthroplasty. J Arthroplasty 2016;31(03):688-693

35 Lutz C, Sonnery-Cottet B, Niglis L, Freychet B, Clavert P, Imbert P. Behavior of the anterolateral structures of the knee during internal rotation. Orthop Traumatol Surg Res 2015;101(05): 523-528

36 Dye SF. The knee as a biologic transmission with an envelope of function: a theory. Clin Orthop Relat Res 1996;(325):10-18

37 Wada K, Mikami H, Hamada D, Yamazaki T, Tomita T, Sairyo K. Can intraoperative kinematic analysis predict postoperative kinematics following total knee arthroplasty? A preliminary. J Med Invest 2017;65(1.2):21-26 